ENCYCLOPEDDE Encyclopédie berbère

BERBERE $36 \mid \mathbf{2 0 1 3}$

$36 \mid$ Oryx - Ozoutae

\title{
Oukaïmeden : Note linguistique
}

Salem Chaker

\section{(2) OpenEdition}

Journals

Édition électronique

URL : https://journals.openedition.org/encyclopedieberbere/2863

DOI : 10.4000/encyclopedieberbere.2863

ISSN : 2262-7197

\section{Éditeur}

Peeters Publishers

\section{Édition imprimée}

Date de publication : 2 juin 2013

Pagination : 5974-5975

ISBN : 978-2-7584-0194-0

ISSN : 1015-7344

\section{Référence électronique}

Salem Chaker, "Oukaïmeden : Note linguistique », Encyclopédie berbère [En ligne], 36 | 2013, document 047, mis en ligne le 12 mars 2021, consulté le 17 février 2022. URL : http://journals.openedition.org/ encyclopedieberbere/2863; DOI : https://doi.org/10.4000/encyclopedieberbere.2863

Ce document a été généré automatiquement le 17 février 2022.

(c) Tous droits réservés 


\title{
Oukaïmeden : Note linguistique
}

\author{
Salem Chaker
}

\section{NOTE DE L'ÉDITEUR}

[Avec les précieuses indications et suggestions de Abdellah Bounfour et Kamal NaïtZerrad]

1 Emile Laoust (d'après les cartes de Jean Dresch) donne la forme Akaimedden qui paraît douteuse (Contribution à une étude de la toponymie du Haut Atlas, Paris, Geuthner, 1942, p. 21, $n^{\circ} 3$ ), à moins que Oukaïmeden [ukayməddən] soit une forme nominale à l'Etat d'Annexion*, qui supposerait un Etat Libre [akayməddən], mais cela ne semble pas correspondre à l'usage des habitants de la région. L'étymologie qu'il en propose est aussi très peu convaincante et inutilement complexe. On en retiendra seulement que le nom berbère du massif est sans aucun doute un composé, qui doit s'analyser en $u / a k a y+$ məddən.

2 Le second élément, məddən, ne pose aucun problème d'identification : c'est un nominal (pluriel à valeur de collectif), très largement répandu dans l'ensemble du berbère : « hommes, gens ».

3 L'analyse du premier composant, ukay, est plus délicate : il est très certainement à rattacher à la racine (verbale) $K Y$, « passer, franchir, dépasser... ». En général, la racine $K Y$ réfère précisément à l'idée de " passer, dépasser (dans l'espace ou le temps) un repère » et le nominal akkay, signifie " passage " (cf. entre autres, ch. de Foucauld, Dictionnaire touareg-français, II, 1952, p. 765/767 ou K. Prasse et al., Dictionnaire touaregfrançais, I, 2003, p. 434. En chleuh, le parler local, le verbe $a k^{\circ} y$ a des sens divers :

- Sauter, bondir, se réveiller » (E. Destaing, Vocabulaire français-berbère, 1938, p. 256 et Textes berbères en parlers des Chleuhs du Sous, Paris, 1940, p. 357);

- « Franchir un gué, un obstacle, sauter, éclore... » (Jordan, Dictionnaire berbère-français, Rabat, 1934, p. 27).

4 Lorsqu'il est associé à la particule de rapprochement $-d\left(a k^{o} y-d\right)$, il peut avoir le sens de « rejoindre ». C'est ce même verbe qui prend en kabyle (et dans de nombreux autres 
dialectes, dont le chleuh, cf. supra) le sens de "s'éveiller, se réveiller» (< «passer de l'état de sommeil à celui de veille »)... Sur ce verbe de mouvement, on se reportera à la très intéressante étude de L. Galand dans : "Libyque et berbère ", Annuaire de l' ЕPHE (Rapport sur les conférences), IV Section, 1977, notamment p. 198.

5 Comme bien souvent en onomastique*, l'analyse ne permet pas d'aboutir à des conclusions certaines et définitives, le statut exact de ukay étant difficile à déterminer. Si on le considère comme un verbe*, il s'agirait d'un singulier (puisqu'il n'est pas accordé avec тәddəП, qui est un pluriel); et l'on sera tenté d'y voir un thème de prétérit ("accompli") à voyelle /A/ (prétérit intensif ?) sur un verbe d'état sans indice de personne : «il dépasse les gens » (?). S'il s'agit d'un nominal*, on le reliera à la forme touarègue mentionnée ci-dessus (akkay, " passage »).

6 L'ensemble ukay+məddən réfère donc à l'idée de "franchissement /dépassement/ passage » + «êtres humains/gens ». C'est une explication sémantique comparable que retient l'Encyclopédie du Maroc qui opte, sans fournir de justification explicite, pour la signification «lieu où les gens se rassemblent ». Le site est effectivement un lieu de rassemblement des tribus en période d'estive.

INDEX

Mots-clés : Géographie, Linguistique, Onomastique 